\title{
Diversidade de gênero e a evasão universitária em cursos de graduação em administração, ciências contábeis, ciências econômicas e sistemas de informação da Universidade Federal de Mato Grosso (UFMT- Campus Rondonópolis)
}

André Luís Janzkovski Cardoso'; Nathália Prochnow Nagai².

\begin{abstract}
Resumo
Esta pesquisa analisa o fenômeno da evasão no ensino superior considerando a diversidade do fator humano, especificamente a variável gênero. Assim, busca-se comparar os motivos que provocaram a evasão de alunos dos cursos de administração, ciências contábeis, ciências econômicas e sistemas de informação da Universidade Federal de Mato Grosso (UFMT-Campus Rondonópolis) levando em conta as percepções de homens e mulheres. Os dados foram coletados por meio de um questionário eletrônico, composto por questões baseadas na escala Likert e por questões abertas, tendo como público-alvo alunos não matriculados em seus respectivos cursos, em dezembro de 2014. Modelos estatísticos, como análise fatorial, comparativo entre médias, correlações foram utilizados, bem como uma análise qualitativa das respostas das questões abertas. Os resultados apontam para diferenças estatisticamente significativas entre os motivos de evasão e o gênero, mas apenas para dois fatores, cidade e aprendizagem. Além disso, os dados qualitativos revelaram problemas em relação à didática em sala de aula e à pressão psicológica proveniente dos professores, a falta de preparo de outros alunos, a falta de professores e o fato de o curso ser novo. Outros problemas identificados foram relacionados à segurança, falta de linhas de pesquisa, projetos de extensão e programa de iniciação científica.
\end{abstract}

Palavras-chave: Evasão; Diversidade; Gênero.

\footnotetext{
${ }^{1}$ Doutor em Administração. Professor do Curso de Administração e do Mestrado em Gestão e Tecnologia Ambiental (Universidade Federal de Mato Grosso, Campus Universitário de Rondonópolis). E-mail: andrecardoso@ufmt.br ORCID: http://orcid.org/0000-0002-6213-8123

${ }^{2}$ Bacharel em Administração e MBA em Finanças e Controladoria pela Universidade Federal de Mato Grosso, Campus Universitário de Rondonópolis. E-mail: nagainathalia@gmail.com ORCID: http://orcid.org/0000-0003-4863-3811
} 


\title{
Gender diversity and university dropout in undergraduate courses in administration, accounting sciences, economics and information systems at the Federal University of Mato Grosso (UFMT - Rondonópolis Campus)
}

\begin{abstract}
This research analyzes the phenomenon of dropout in higher education considering the diversity of the human factor, specifically the gender variable. Thus, it is sought to compare the reasons that has provoked the dropout of students from the courses of administration, accounting sciences, economics and information systems of the Federal University of Mato Grosso (UFMT-Campus Rondonópolis) taking into account the perceptions of men and women. The data were collected through an electronic questionnaire, composed of questions based on Likert scale and for open questions, considering as public target students not enrolled in their respective courses, in December 2014. Statistical models, such as factorial analysis, comparative among averages, correlations were used, as well a qualitative analysis of the answers from open questions. The results point to statistically significant differences between the reasons for dropout and gender, but only for two factor, source-city and learning. In addition, the qualitative data revealed problems regarding classroom didactic and the psychological pressure coming from teachers, the lack of preparation of other students, the lack of teachers, and the fact that the course was new. Other problems identified were related to the safety and lack of research's lines, extension projects and scientific initiation.
\end{abstract}

Keywords: Dropout; Diversity; Gender.

JEL: M; M1; M14.

\section{Considerações Iniciais}

A evasão nas escolas, em geral e no ensino superior em específico, é um fenômeno complexo que envolve diversas variáveis e que tem sido tema recorrente de discussões sobre suas causas, seus efeitos e como minimizá-los.

$\mathrm{Na}$ literatura, pode-se observar a evolução do tema ao longo do tempo, abordando a evasão tanto na visão dos evadidos quanto na visão dos professores e coordenadores de curso. Estudos voltados ao ensino superior trazem alguns motivos que levam os alunos a desistirem de seus cursos, entre eles são indicados os problemas pessoais e financeiros, a mudança de cidade, a não identificação com o curso e com o futuro trabalho. Compreender o porquê da evasão é o primeiro passo para buscar medidas de melhoria e retenção dos alunos no ensino superior, pois a evasão não traz consequências apenas para 
os evadidos, mas também para a instituição de ensino e para a sociedade de uma forma geral.

Para Baggi e Lopes (2011) o fenômeno da evasão tem preocupado as instituições de ensino em geral, sejam públicas ou particulares, porque a saída de alunos provoca graves consequências sociais, acadêmicas e econômicas. As universidades se tornam menos eficientes com a evasão de seus alunos, pois a maioria dos recursos financeiros são consumidos, independentemente, do número de alunos em sala de aula, o que leva as instituições de ensino a falhar com o seu objetivo principal de formar cidadãos capazes de contribuir para o desenvolvimento de uma sociedade. A sociedade por sua vez perde na quantidade de capital social que poderia ser gerado no ambiente acadêmico tendo em vista que nem todos os alunos conseguem concluir seus cursos. Assim, o aluno que não completa o ensino superior tem redução do seu nível de empregabilidade e pode desenvolver sentimentos de fracasso, frustração e de incapacidade intelectual, algumas vezes limitando o seu progresso sócio financeiro e também de seus familiares.

A questão da evasão também pode ser discutida em termos de peculiaridades dos alunos evadidos. Pode-se estar interessado em saber as características dos indivíduos, as causas de evasão por grupos pré-determinados, além de aspectos demográficos que possam ajudar na compreensão deste fenômeno. Um desses aspectos poderia estar relacionado à diversidade do fato humano, por exemplo, quanto ao gênero.

Desta forma, a problemática desta pesquisa é descobrir quais são os fatores que levam os estudantes e as estudantes dos cursos de Administração, Ciências Econômicas, Ciências Contábeis e Sistemas de Informação a evadirem da Universidade Federal de Mato Grosso, Campus Universitário de Rondonópolis (UFMT/CUR). Como objetivos específicos, este artigo busca levantar os dados das alunas participantes da pesquisa e comparar com os dados dos alunos; analisar os fatores que levam as alunas a deixarem seus cursos; discutir as questões abertas no tocante a evidenciar ou exemplificar o sentimento das alunas acerca dos motivos de deixarem seus cursos. A hipótese desta pesquisa é que há diferenças entre os fatores que levam alunas e alunos a deixarem seus cursos.

A coleta de dados foi realizada em dois momentos diferentes por meio de entrevistas com os coordenadores dos cursos utilizando de um roteiro semiestruturado, e em um segundo momento, foram enviados por e-mail um questionário eletrônico a uma lista de alunos e alunas considerados evadidos. No tratamento de dados foram utilizados modelos estatísticos abrangendo análise fatorial, comparativo entre médias e análise de correlação, além de uma análise qualitativa das respostas às perguntas abertas e comentários dos respondentes. A partir disso, os resultados são discutidos à luz do referencial teórico e de estudos anteriores. 
Este trabalho contribui de forma teórica à medida que traz uma discussão sobre as possíveis razões de evasão na visão de alunos e coordenadores dos cursos. Além disso, busca particularizar questões envolvendo o gênero e a saída de alunos e alunas do ensino superior. A contribuição prática constitui de informações, tanto para os coordenadores de curso quanto para a administração superior da universidade, que podem se valer das mesmas para tomar medidas para que os alunos sejam retidos.

Assim, este artigo foi dividido em cinco partes, esta contextualização inicial, um referencial teórico apresentando os principais conceitos e estudos anteriores sobre evasão no ensino superior, os procedimentos metodológicos, a análise dos dados e a discussão dos resultados e, finalmente, as considerações finais.

\section{Referencial Teórico}

O referencial teórico deste artigo é composto pela conceituação de evasão universitária e de diversidade do fator humano, incluindo estudos anteriores sobre essas temáticas.

\subsection{Evasão Universitária}

Pode-se definir evasão como a saída definitiva e prematura de um aluno de seu curso de origem (ADACHI, 2009). Detalhando este conceito, Silva Filho et al. (2007) identifica diferentes perspectivas sobre o tema, sendo a evasão anual média, medida pela percentagem de alunos matriculados em um curso que ainda não são egressos, mas que não se matricularam no ano seguinte; como também a evasão total medida pelo número de alunos que, tendo entrado em um curso, não obtiveram o diploma depois de um determinado número de anos.

Para Ribeiro (2005) a evasão se caracteriza pelo desligamento de alunos em um sistema de ensino superior, sem nenhuma transferência interna ou externa a outra organização de ensino superior. Para Mello et al. (2012) a evasão se caracteriza quando um aluno que ingressou em uma IES e que não solicitou matrícula em disciplinas em semestres consecutivos ou ainda no caso daqueles alunos que, formalmente, pediram o cancelamento de suas matrículas. 
Uma visão mais específica, como a de Barroso e Falcão (2004), entende que o termo evasão estaria associado a um processo de abandono de estudos por parte de um aluno de qualquer curso dentro da instituição, independente de iniciar outro curso na mesma instituição. Já uma caraterização mais ampla, pode-se considerar a proposta de Pereira (1996) indicando três formas diferentes de evasão, da Universidade, da área do conhecimento e do curso propriamente dito. A Evasão da Universidade remonta ao aluno que deixa a universidade sem concluir nenhum curso, incluindo abandono, cancelamento de matrícula ou transferência para outra universidade. A evasão de Área pode ser entendida quando há mobilidade dentro da mesma instituição, porém para diferente área do conhecimento, e a evasão de Curso é quando há a troca por outro curso na mesma área ou não.

Segundo a Comissão Especial de Estudos sobre Evasão (1996), são três tipos de Evasão: de Curso, da Instituição e de Sistema. Os dois primeiros tipos são iguais aos indicados por Pereira (1996), já a evasão de Sistema é aquela representada pela saída de um aluno, definitiva ou temporária, do ensino superior. Em síntese, as principais definições encontradas na revisão de literatura, conforme Pereira (1996) e Comissão Especial de Estudos sobre Evasão (1996), são:

- Evasão da Universidade ou Instituição: desligamento do aluno com a instituição em que estava matriculado.

- Evasão de Área: quando há mobilidade do aluno na própria instituição, porem em outra área do conhecimento diferente de seu curso de origem.

- Evasão de Curso: é a saída definitiva do aluno de um curso de origem.

- Evasão do Sistema: é a saída definitiva ou mesmo temporária do aluno do ensino superior, a partir da ausência de matrícula entre semestres.

Além disso, Prestes, Fialho e Pfeiffer (2014) indicam três perdas provocadas pela evasão, sociais, econômicas e o descumprimento com os objetivos institucionais na formação de cidadãos, especialmente as universidades públicas, pois seus orçamentos anuais são calculados a partir do montante de alunos matriculados, porém, ao longo do tempo, muitos alunos abandonam a instituição sem concluir seus cursos. Há então uma ineficiência com os recursos públicos, no tocante que as universidades mantêm a mesma estrutura projetada para atender a maior número de estudante que efetivamente são atendidos. Salienta-se que com a evasão, a universidade falha em cumprir a missão de formar pessoas que contribuam com a sociedade, o progresso e desenvolvimento da nação. 


\subsection{Estudos anteriores acerca do tema "evasão"}

Em um levantamento não exaustivo nas bases de Dados da SPELL e Scielo proporcionou a identificação de uma série de estudos sobre o tema evasão (AMBIEL, 2015; AMBIEL; SANTOS; DALBOSCO, 2016; BAGGI; LOPES, 2011; BARDAGI; HUTZ, 2005; BARDAGI; HULZ, 2009; BERGAMO; FARAH; GIULIANI, 2007; COSTA; BISPO; PEREIRA, 2018; CUNHA et al., 2015; CUNHA; NASCIMENTO; DURSO, 2016; FURTADO; ALVES, 2012; MENDONÇA et al., 2012; NAGAI; CARDOSO, 2017; PLATT NETO; CRUZ; PFITSCHER, 2008; RODRIGUES; SANTOS; SANTANA, 2015; SCHUARCZ et al., 2011; SILVA FILHO et al., 2007; VILLAS BÔAS, 2003).

O primeiro artigo, em ordem cronológica de sua publicação, é o trabalho de Villas Bôas (2003) cujo foco foi a evasão do curso de ciências sociais da Universidade Federal do Rio de Janeiro, fazendo uma análise histórica e a associando com as mudanças curriculares em cinquenta anos de curso. A autora salienta que mesmo os currículos acumulando mais matérias e disciplinas, não houve indício de redução do nível alarmante de evasão na ordem de 50\% de alunos. Porém, dos alunos que participaram da experiência do Programa de Iniciação Científica entre 1988-1997 apenas 2\% deixaram o curso e a maioria dos egressos do programa se dedicam a atividades profissionais no campo das ciências sociais.

Já o artigo de Bardagi e Hutz (2005), utilizando-se de pesquisa qualitativa com alunos evadidos, identificou a fragilidade das escolhas iniciais, a pouca atividade exploratória e as expectativas irrealistas de carreira desses alunos. Os autores salientam a necessidade de criação de estratégias por parte das universidades dialogando sobre as expectativas futuras de seus alunos, além de prestar serviços de apoio ao estudante universitário como maneiras de reduzir a evasão.

Silva Filho et al. (2007) consolidando dados de 2001 a 2005 retrataram que a taxa de evasão no Brasil era da ordem de $22 \%$ dos ingressantes no ensino superior. A evasão anual nas IES públicas oscilou em torno dos $12 \%$, variando entre 9 e $15 \%$ no período, enquanto as IES privadas mostraram uma oscilação em torno de $26 \%$. Os autores ainda salientaram que a região Norte teve a menor taxa de evasão (16\%) e a maior taxa de evasão foi o Centro-Oeste do Brasil com 23\%. Mato Grosso do Sul, Mato Grosso e Goiás tiveram taxas médias de evasão anual oscilantes. Goiás ficou na média, com uma evasão menor que a regional e a nacional, já Mato Grosso e Mato Grosso do Sul tiveram médias ligeiramente acima da regional e da nacional. 
Outros estudos procuraram apresentar estratégias para reduzir o nível de abandono no ensino superior, tais como as pesquisas de Bergamo, Farah e Giuliani (2007), Mendonça et al.(2012) outros discutem problemas e riscos associados à utilização do índice de evasão escolar como meta para avaliação de desempenho institucional no contexto do ensino superior público. Alguns estudos retratam a percepção dos alunos evadidos em cursos como secretariado, ciências contábeis e administração (CUNHA et al., 2015; CUNHA; NASCIMENTO; DURSO, 2016; MENDONÇA et al., 2012; RODRIGUES; SANTOS; SANTANA, 2015; SCHUARCZ et al., 2011), já outros analisam especificamente a evasão em alunos de determinadas instituições de ensino superior (COSTA; BISPO; PEREIRA, 2018; FURTADO; ALVES, 2012) e Baggi e Lopes (2011) analisaram a produção teórica sobre a evasão e a sua relação com a avaliação institucional a partir da Biblioteca Digital de Teses e Dissertações (BDTD) entre os anos de 2008 e 2009. Os autores indicaram que a relação entre evasão e avaliação foi pouco estudada no período, sendo ainda mais restrita que as reflexões sobre o fenômeno da evasão no ensino superior.

Ambiel (2015) propôs uma escala de motivos para evasão no ensino superior, a partir de artigos brasileiros, e na vivência de estudantes ativos e evadidos de instituições públicas e particulares. O autor identificou sete componentes principais, com 65 itens ao todo. Já no estudo de Ambiel, Santos e Dalbosco (2016) foram utilizados os instrumentos Questionário de Vivência Acadêmica- Reduzido (QVA-r), Escala de Adaptabilidade de Carreira (CAAS) e Escala de Motivos para Evasão do Ensino Superior (M-ES). Os resultados mostraram que o modelo incluindo os fatores do QVA-r e da CAAS, simultaneamente, seria o mais adequado na predição dos fatores da M-ES de motivos relacionados à Carreira, ao Desempenho Acadêmico, ao Interpessoal e à Autonomia, explicando entre $14,3 \%$ e $19 \%$ da variância.

De maneira semelhante, Nagai e Cardoso (2017) construíram uma escala de razões de evasão e a testaram em um grupo de alunos dos cursos de administração, ciências contábeis, ciências econômicas e sistemas de informação. A escala foi validada contendo 8 fatores principais e 29 assertivas, resultando em um instrumento parcimonioso para identificar as razões de evasão de alunos do ensino superior.

Após a apresentação de estudos envolvendo o tema evasão, busca-se associá-lo ao conceito de diversidade que é apresentado a seguir. 


\subsection{Diversidade do fator humano}

O conceito de diversidade tem passado por redefinições desde os primeiros autores que iniciaram as discussões nos Estados Unidos, mas Thomas Jr. (1996, p.6) apresenta uma definição simples e ao mesmo tempo profunda "diversidade não é sinônimo de diferenças, mas inclui diferenças e similaridades". Em uma perspectiva micro, observam-se os aspectos individuais e as diferenças, em uma perspectiva macro são observadas as similaridades da mistura. $\mathrm{O}$ autor reforça esse conceito indicando que a diversidade está associada à coletividade de tudo incluído o que remonta ao trecho publicado anteriormente indicando ser "uma mistura de diferenças e similaridades ao longo de uma dimensão" (THOMAS Jr., 1996, p.7). Disso resulta uma necessidade premente quando se vai tratar de diversidade, pois, deve-se indicar claramente o objeto em análise, sejam eles, produtos, estratégias empresariais ou a diversidade do fator humano, as pessoas componentes de um determinado grupo ou organização. Para Hanashiro (2008) é fundamental se especificar os elementos constituintes de uma mistura (diversidade) a partir de suas dimensões e fontes de diversidade.

Assim, caracterizar um grupo de pessoas como sendo diverso passaria por indicar suas fontes de diversidade, como por exemplo, gênero, raça, etnia, idade, escolaridade, origem, valores, crenças, nível social e pela sua diversidade em si, expressa pelas diferenças e similaridades entre os seus membros. De acordo com Hanashiro et al. (2004), o conceito de diversidade remete às características humanas que fazem as pessoas únicas e diferentes umas das outras, considerando o conjunto da obra, peculiaridades de cada um dos seres humanos que é formado por características físicas, mentais, intelectuais que podem ser tanto similares a um conjunto de características de outras pessoas quanto diferentes de outro conjunto.

Ademais, segundo Ely e Thomas (2001) e Harrison, Price e Bell (1998), há uma distinção entre diversidade superficial que está relacionada às características visíveis e a diversidade profunda aquela não visível cujos aspectos são intangíveis. Há ainda outra subdivisão de tipos de diversidade em termos de suas dimensões primárias ou secundárias. As primárias são constituídas por características pouco controláveis e biologicamente determinadas (raça, gênero, idade, família e sociedade), já as secundárias são aquelas características que as pessoas adotam, eliminam ou alteram durante suas vidas, por meio de escolhas conscientes e esforços pessoais como a escolaridade, a experiência, as crenças políticas e religiosas, o estado civil, a localização geográfica e a renda. 
Especificamente sobre a diversidade de gênero, estudos revelam não haver diferenças entre homem e mulher em termos de atitudes psicológicas no trabalho e poucas diferenças em termos de resposta às solicitações do trabalho. Se por um lado, segundo Stockdale e Crosby (2006), o contexto do trabalho é que é determinante para as reações dos empregados, independentemente do gênero, por outro lado, são as mulheres que sofrem mais problemas por falta de oportunidades, preconceitos, assédios moral e sexual, comparativamente aos homens.

Uma visão crítica sobre envolvendo gerenciamento de questões envolvendo o gênero tem lançado reflexões em alguns pesquisadores. Marshall (1995) as pesquisas sobre gênero nas organizações, indicando que tais estudos têm se tornado saturados pela influência das idealizações masculinizadas, e pelo poder do masculino como norma. A autora indica como problema que as mulheres no início de carreira procuram provar sua competência para ganhar igualdade junto aos homens, mas que mesmo que essas mulheres possam ter estilos de liderança, motivações para o trabalho e aspirações de carreira semelhante aos homens, nem sempre são consideradas como gerentes legítimas.

Uma tendência dessa teorização sugere que muitas mulheres possuem estilos de gestão mais interativa do que os colegas do gênero masculino e este comportamento tem sido moldado pelo debate semelhança-diferença. $\mathrm{O}$ caminho da argumentação é provar que mulheres, por vezes, são diferentes dos homens e defender a igualdade de direitos de serem diferentes e a legitimidade dessas diferenças. Segundo Marshall (1995), pesquisadores enfrentam desafios sobre como lidar com as diferenças aparentes entre homens e mulheres de forma ampla ou, especificamente, como parte de um grupo social definido. Diferenças tais como, homens são mais propensos a se preocupar com questões de hierarquia e status e mulheres com questões de igualdade de participação e relacionamento, são exemplos indicados por Marshall (1995) como algumas das diferenças identificadas. Pesquisadores de gênero, então, necessitam de teorias complexas e sutis sobre mudança organizacional e social capazes de apreciar a resiliência, a dinâmica sistêmica, os processos de poder e as suas relações.

Apesar de ações de igualdade de oportunidades e de exemplos de mulheres atuando em cargos gerenciais, pouco se alterou em termos de modelos e estilos de liderança aceitos, modelos de carreira e de práticas do trabalho (MARSHALL, 1995). A literatura sobre o desenvolvimento das mulheres indica a necessidade de um debate amplo em um mundo inteiramente dominado por homens, em que os significados para as mulheres precisam ser compreendidos e valorizados. 
Mais especificamente, na busca por pesquisas científicas envolvendo gênero, e evasão, poucos são os artigos que versão sobre as duas temáticas simultaneamente. Temse o estudo de Borges (2011) em que o autor identificou as diferentes percepções entre os gêneros em relação aos fatores problemáticos do curso de administração da ULBRA. Para o gênero feminino os fatores como a falta de preparação do profissional para o mercado de trabalho, horários e mudança de currículo são considerados aspectos relevantes para a decisão de deixar o curso. Para o gênero masculino a matriz curricular foi o maior apontamento. Já Nagai e Cardoso (2017) identificaram haver diferenças estatisticamente significativas entre algumas razões de evasão, envolvendo fatores como Cidade e Aprendizado e o gênero dos respondentes.

Contudo, a maioria dos estudos sobre evasão não identifica se há diferenças nas percepções de acordo com o gênero, pois as pesquisas apenas apresentam o número de evadidos, que na maioria dos casos pesquisados são homens, conforme apontado no estudo de Mello et al. (2012). A limitação de estudos envolvendo evasão e diversidade de gênero é uma oportunidade para este artigo cujo objetivo é descobrir quais são os fatores que levam os estudantes e as estudantes dos cursos de Administração, Ciências Econômicas, Ciências Contábeis e Sistemas de Informação a evadirem da UFMT/CUR, e para alcançar esse objetivo, o passo a passo da pesquisa é delineado a seguir.

\section{Procedimentos Metodológicos}

O público alvo desse estudo foram os alunos e alunas registrados entre os anos de 2010 a 2014 nos cursos de Administração, Ciências Econômicas, Ciências Contábeis e Sistemas de Informação que não estavam matriculados em dezembro de 2014, totalizando assim 877 alunos, que depois de eliminar duplicidades, resultou em 792 alunos. Desse total, 234 eram do curso de administração, 211 do curso de ciências econômicas, 183 do curso de ciências contábeis e 164 do curso de sistemas de informação. Os cursos foram escolhidos devido às afinidades entre si, já que são cursos relacionados às ciências empresariais.

O questionário da pesquisa foi criado a partir dos estudos de Gomes (1999), Mazzetto e Carneiro (2002), Ataíde, Lima e Alves (2006), Machado (2009), Borges (2011), Mello et al. (2012) e Mendonça et al. (2012). As perguntas do questionário foram refinadas após entrevistas realizadas com os coordenadores dos cursos para identificar outras possíveis razões de evasão. O questionário foi dividido em quatro blocos principais, sendo o primeiro sobre dados demográficos e perfil do respondente, o segundo incluía a forma de ingresso e a escolha do curso pelo aluno, o terceiro caracterizando aspectos relacionados à evasão e o último perguntando sobre a situação momentânea do respondente, além da possibilidade de incluir comentários. 
As possíveis razões foram retiradas ou adaptadas de estudos anteriores totalizando 29 assertivas, como se pode observar no Quadro 1. Por meio de uma escala Likert de 11 pontos (0 a 10), os alunos deveriam sinalizar as razões que influenciaram a decisão em deixar o curso. O questionário foi enviado por e-mail aos alunos e as respostas válidas totalizaram 184, ou seja, $23 \%$ do total de alunos não matriculados, ou ainda, $30 \%$ dos emails corretos, dado que vários e-mails estavam errados ou desatualizados.

Quadro 1 - Possíveis razões de evasão no ensino superior a partir do levantamento do referencial teórico

\begin{tabular}{|c|c|c|}
\hline Grupo & Assertivas & Autores \\
\hline $\begin{array}{l}\text { Estrutura do Curso ou da } \\
\text { Instituição de Ensino }\end{array}$ & $\begin{array}{c}\text { Greve } \\
\text { Instalações inadequadas } \\
\text { Falta de material bibliográfico } \\
\text { Estrutura curricular } \\
\text { Qualidade dos professores } \\
\text { Prestígio do curso na cidade } \\
\text { Sobrecarga de atividades } \\
\text { Método dos professores } \\
\text { Relacionamento entre aluno e aluno } \\
\text { Relacionamento entre aluno e professor }\end{array}$ & $\begin{array}{l}\text { Gomes (1999); Mazzetto e } \\
\text { Carneiro (2002); Machado } \\
\text { (2009); Mello et al. (2012); } \\
\text { Ataíde, Lima e Alves (2006) }\end{array}$ \\
\hline $\begin{array}{c}\text { Mercado de Trabalho e } \\
\text { Carreira }\end{array}$ & $\begin{array}{c}\text { Expectativa de baixa remuneração após concluir o curso } \\
\text { Pouca opção de emprego } \\
\text { Descobri que não tinha vocação para o curso } \\
\text { Escolha inadequada do curso } \\
\text { Falta de conhecimento sobre o curso escolhido }\end{array}$ & $\begin{array}{l}\text { Gomes (1999); Mazzetto e } \\
\text { Carneiro (2002); Mendonça } \\
\text { (2012); Borges (2011) }\end{array}$ \\
\hline Trabalho e Localidade & $\begin{array}{c}\text { Dificuldade em conciliar estudo e trabalho } \\
\text { Oferta de emprego ou promoção } \\
\text { Localização da Instituição } \\
\text { Mudança de cidade } \\
\text { Dificuldades em adaptar-se em uma nova cidade }\end{array}$ & $\begin{array}{l}\text { Borges (2011); Gomes (1999); } \\
\text { Mello et al. (2012) }\end{array}$ \\
\hline Pessoal, Família e Finanças & $\begin{array}{c}\text { Dificuldade em se manter somente estudando } \\
\text { Dificuldades em se manter em uma nova cidade } \\
\text { Gravidez } \\
\text { Casamento } \\
\text { Para cuidar de filhos } \\
\text { Doença }\end{array}$ & $\begin{array}{l}\text { Machado (2009); Mendonça } \\
\text { (2012); Ataíde, Lima e Alves } \\
\text { (2006); Borges (2011); Mello et } \\
\text { al. (2012) }\end{array}$ \\
\hline Outras Razões & $\begin{array}{c}\text { Mudança de Curso } \\
\text { Acúmulo de reprovações } \\
\text { Dificuldades de Aprendizado }\end{array}$ & Ataíde, Lima e Alves (2006) \\
\hline
\end{tabular}

Fonte: Elaboração própria a partir dos autores indicados 
Para o tratamento dos dados, utilizou-se o software SPSS 20 (Statistical Package of Social Sciences) por meio das técnicas de análise fatorial, análise de correlação e comparativo entre médias. De acordo com Field (2009) a análise fatorial busca identificar agrupamentos de dados com características similares e tem três usos principais, entender a estrutura de um conjunto de variáveis, construir um questionário para medir uma variável subjacente ou reduzir um conjunto de dados a um tamanho mais manejável. Os dados e os resultados são apresentados e discutidos na próxima sessão.

\section{Apresentação e discussão dos dados}

Para nortear a discussão sobre os fatores que levam alunos e alunas a deixarem a universidade, apresentam-se os dados estatísticos e demográficos sobre gêneros oriundos do censo do IBGE datado do ano de 2010. O Censo de 2010 revela que em Rondonópolis entre os anos de 2000 e 2010 houve um aumento dos índices de nível de escolaridade, ocupação e renda tanto de homens quanto de mulheres, conforme Figuras 1, 2 e 3.

Quanto ao nível de escolaridade ensino superior completo, entre 2000 e 2010, as mulheres tiveram um crescimento de $245 \%$ frente a um crescimento de $175 \%$ dos homens. Quanto à ocupação, as mulheres também sobressaíram diante dos homens com $210 \%$ de aumento frente a $159 \%$ dos homens.

Todavia, conforme a Figura 3, a renda média dos homens é superior à das mulheres em todas as faixas salariais. O que se percebe é que com o aumento da renda média, a distância entre renda de homens e mulheres, mesmo ainda sendo bem díspares, tende a se reduzir. Por isso, tendo como premissa que há certa correlação entre nível de escolaridade e renda, entende-se que a evasão de mulheres no ensino superior tende a reduzir a possibilidade de uma equidade de renda entre gênero, fato este que aumenta a relevância deste estudo.

Figura 1 - Nível de Escolaridade de Homens e Mulheres de Rondonópolis entre 2000 e 2010

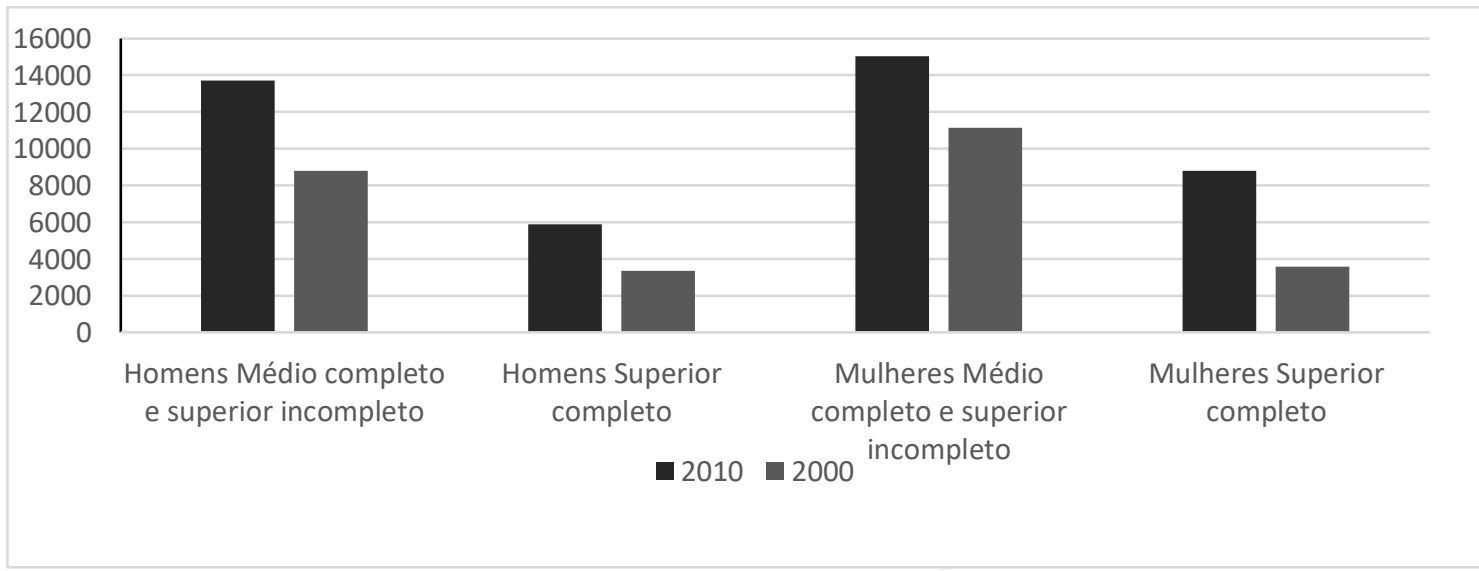

Fonte: IBGE (2011). 
Figura 2 - Ocupação de Homens e Mulheres de Rondonópolis entre 2000 e 2010

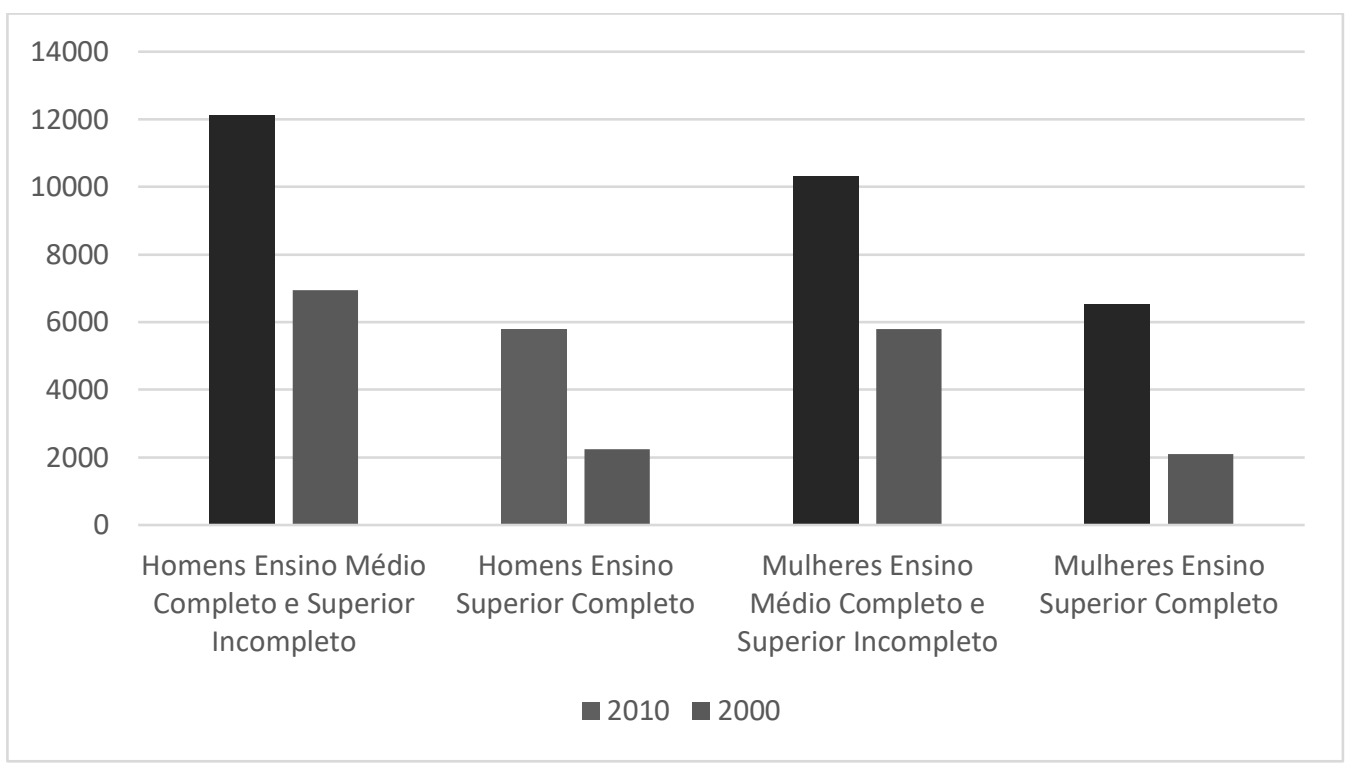

Fonte: IBGE (2011)

Figura 3 - Renda média de Homens e Mulheres de Rondonópolis em 2010

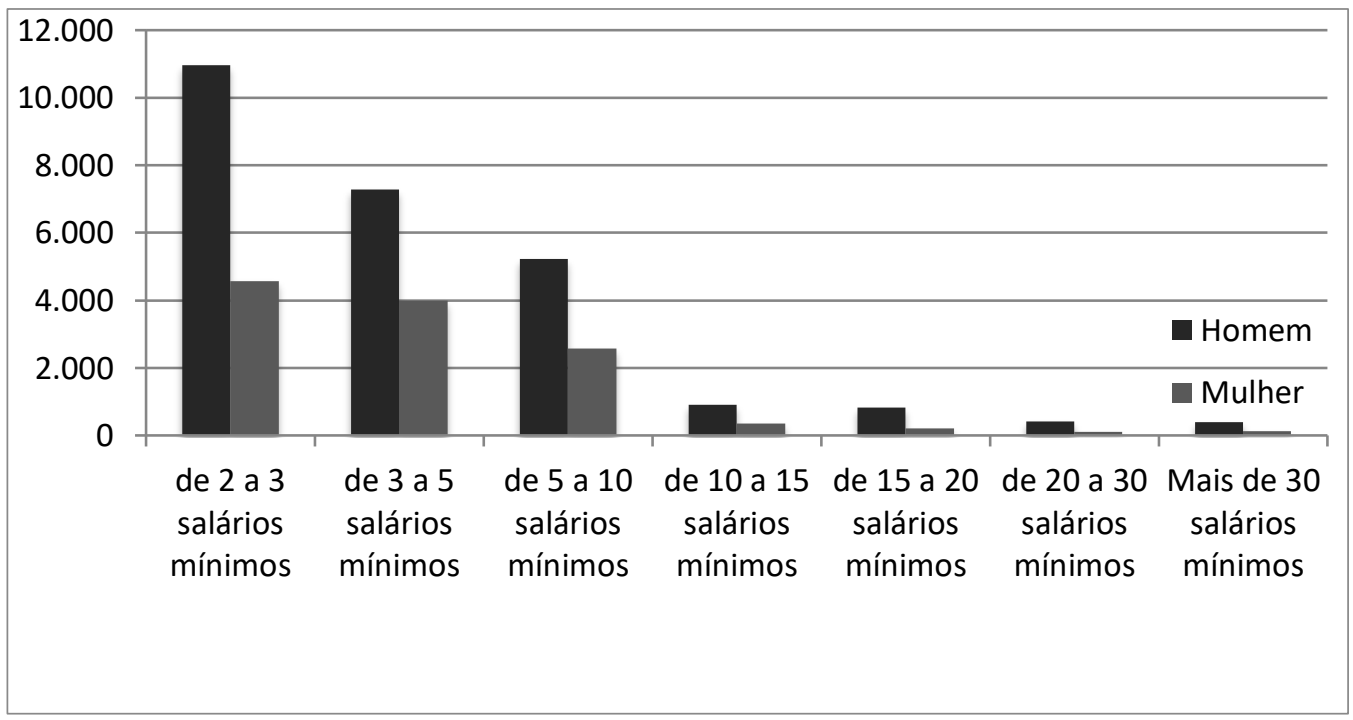

Fonte: IBGE (2011)

No levantamento realizado no sistema da Universidade, foram identificados os alunos e alunas matriculados e aqueles que não estavam matriculados. Uma segunda divisão, separou em gênero, conforme Tabela 1. 
Tabela 1 - Levantamento do número de alunos e alunas matriculados e evadidos e sua relação por curso e ao longo dos anos

\begin{tabular}{|c|c|c|c|c|c|c|c|c|c|c|c|c|}
\hline \multirow{2}{*}{ Matriculados } & \multicolumn{2}{|c|}{2010} & \multicolumn{2}{|c|}{2011} & \multicolumn{2}{|c|}{2012} & \multicolumn{2}{|c|}{2013} & \multicolumn{2}{|c|}{2014} & \multicolumn{2}{|c|}{ Total } \\
\hline & $\mathbf{H}$ & $\mathbf{M}$ & $\mathbf{H}$ & $\mathbf{M}$ & $\mathbf{H}$ & M & $\mathbf{H}$ & $\mathbf{M}$ & $\mathbf{H}$ & $\mathbf{M}$ & $\mathbf{H}$ & $\mathbf{M}$ \\
\hline Administração & & & 15 & 23 & 24 & 25 & 16 & 46 & 34 & 60 & 89 & 154 \\
\hline Ciências Contábeis & 16 & 29 & 19 & 27 & 27 & 37 & 26 & 47 & 42 & 63 & 130 & 203 \\
\hline Ciências Econômicas & 13 & 6 & 19 & 21 & 19 & 16 & 30 & 25 & 29 & 27 & 110 & 95 \\
\hline Sistemas de Informação & & & 28 & 4 & 40 & 3 & 53 & 10 & 55 & 13 & 176 & 30 \\
\hline Total & 29 & 35 & 81 & 75 & 110 & 81 & 125 & 128 & 160 & 163 & 505 & 482 \\
\hline \multirow{2}{*}{ Evadidos } & \multicolumn{2}{|c|}{2010} & \multicolumn{2}{|c|}{2011} & \multicolumn{2}{|c|}{2012} & \multicolumn{2}{|c|}{2013} & \multicolumn{2}{|c|}{2014} & \multicolumn{2}{|c|}{ Total } \\
\hline & $\mathbf{H}$ & $\mathbf{M}$ & $\mathbf{H}$ & $\mathbf{M}$ & $\mathbf{H}$ & $\mathbf{M}$ & $\mathbf{H}$ & $\mathbf{M}$ & $\mathbf{H}$ & $\mathbf{M}$ & $\mathbf{H}$ & $\mathbf{M}$ \\
\hline Administração & & & 40 & 37 & 38 & 27 & 27 & 28 & 15 & 22 & 120 & 114 \\
\hline Ciências Contábeis & 24 & 23 & 23 & 24 & 26 & 21 & 18 & 14 & 5 & 5 & 96 & 87 \\
\hline Ciências Econômicas & 19 & 6 & 33 & 22 & 36 & 31 & 26 & 15 & 13 & 10 & 127 & 84 \\
\hline Sistemas de Informação & & & 44 & 9 & 37 & 11 & 30 & 9 & 16 & 8 & 127 & 37 \\
\hline Total & 43 & 29 & 140 & 92 & 137 & 90 & 101 & 66 & 49 & 45 & 470 & 322 \\
\hline \multirow{2}{*}{ Relação Evadidos/Matriculados } & \multicolumn{2}{|c|}{2010} & \multicolumn{2}{|c|}{2011} & \multicolumn{2}{|c|}{2012} & \multicolumn{2}{|c|}{2013} & \multicolumn{2}{|c|}{2014} & \multicolumn{2}{|c|}{ Total } \\
\hline & $\mathbf{H}$ & $\mathbf{M}$ & $\mathbf{H}$ & $\mathbf{M}$ & $\mathbf{H}$ & $\mathbf{M}$ & $\mathbf{H}$ & $\mathbf{M}$ & $\mathbf{H}$ & $\mathbf{M}$ & $\mathbf{H}$ & $\mathbf{M}$ \\
\hline Administração & & & $2-7$ & $1-6$ & $1-6$ & $1-1$ & $1-7$ & $0-6$ & $0-4$ & $0-4$ & $1-3$ & $0-7$ \\
\hline Ciências Contábeis & $1-5$ & $0-8$ & $1-2$ & $0-9$ & $1-0$ & $0-6$ & $0-7$ & $0-3$ & $0-1$ & $0-1$ & $0-7$ & $0-4$ \\
\hline Ciências Econômicas & $1-5$ & $1-0$ & $1-7$ & $1-0$ & $1-9$ & $1-9$ & $0-9$ & $0-6$ & $0-4$ & $0-4$ & $1-2$ & $0-9$ \\
\hline Sistemas de Informação & & & $1-6$ & $2-3$ & $0-9$ & 3-7 & $0-6$ & $0-9$ & $0-3$ & $0-6$ & $0-7$ & $1-2$ \\
\hline Relação Total & $1-5$ & $0-8$ & $1-7$ & $1-2$ & $1-2$ & $1-1$ & $0-8$ & $0-5$ & $0-3$ & $0-3$ & $0-9$ & $0-7$ \\
\hline
\end{tabular}

Fonte: Elaboração própria

Alguns pontos merecem ser salientados. Os Cursos de Administração e Sistemas de Informação iniciaram suas operações no ano de 2011, por isso não há informações de matriculados e evadidos em 2010. O número de alunos matriculados flutua próximo de $50 \%$ entre homens e mulheres, especialmente nos últimos anos analisados. Quanto ao número de evadidos, foi considerado o ano do ingresso dos alunos para parâmetro, desta forma, pode-se interpretar a Tabela 1 salientando, por exemplo, que 140 homens e 92 mulheres que ingressaram em seus cursos em 2011, foram considerados evadidos por não estarem matriculados em 2014. Da mesma forma, dos ingressantes de 2014, 49 homens e 45 mulheres não se matricularam novamente em seus cursos. Quando se calcula a relação entre número de alunos e alunas evadidos e matriculados, considerando o ano de ingresso novamente como parâmetro, chega-se a relações preocupantes, como por exemplo, para os alunos que ingressaram em administração no ano de 2011, a cada 2,7 homens, apenas 1 ainda está matriculado e a cada 1,6 mulheres apenas 1 permanece matriculada. Ou seja, quanto maior a relação apresentada na Tabela 1, pior é a situação com maior número de abandonos. Assim, o Curso de Ciências Contábeis apresenta, ao longo dos anos analisados, a melhor relação evadido/matriculado (0,7 para homens e 0,4 para mulheres). Os dados revelam também que, no geral, há maior evasão de homens nos quatro cursos analisados. 
Após a totalização das respostas dos evadidos, iniciou-se o processo de tabulação. Os dados desta pesquisa, contando com 184 respondentes, indicaram a participação de 65 mulheres (35\%) e 119 homens (65\%), com idade média de 26 anos (desvio padrão de cerca de 7 anos). Em relação ao estado civil, a maioria dos respondentes é de solteiros, totalizando $112(61 \%)$. Os respondentes que cursaram o ensino médio em instituição pública totalizaram 157 (85\%), enquanto os que cursaram em instituição particular totalizaram apenas $27(15 \%)$, conforme mostrado na Tabela 2.

Tabela 2 - Dados demográficos dos respondentes

\begin{tabular}{|c|c|c|c|c|c|c|c|c|c|}
\hline \multirow[t]{2}{*}{ Curso } & \multicolumn{2}{|c|}{ Gênero } & \multicolumn{2}{|r|}{ Idade } & \multicolumn{3}{|c|}{ Estado Civil } & \multicolumn{2}{|c|}{ Ensino Médio } \\
\hline & Feminino & Masculino & Média & Desvio Padrão & Solteiro & Casado & Outro & Público & Particular \\
\hline Administração & 28 & 34 & $26-5$ & $6-5$ & 38 & 23 & 1 & 49 & 13 \\
\hline $\begin{array}{l}\text { Ciências } \\
\text { Contábeis }\end{array}$ & 14 & 23 & 24-1 & $4-8$ & 26 & 8 & 3 & 31 & 6 \\
\hline $\begin{array}{l}\text { Ciências } \\
\text { Econômicas }\end{array}$ & 18 & 38 & $26-8$ & $8-7$ & 32 & 20 & 4 & 50 & 6 \\
\hline $\begin{array}{l}\text { Sistemas de } \\
\text { Informação }\end{array}$ & 5 & 24 & $27-6$ & $7-5$ & 16 & 8 & 5 & 27 & 2 \\
\hline Total & 65 & 119 & $26-3$ & $7-2$ & 112 & 59 & 13 & 157 & 27 \\
\hline
\end{tabular}

Fonte: Elaboração própria

Os resultados das análises fatoriais deste estudo indicaram oitos fatores relacionados à evasão. Para a análise fatorial foi utilizado o método de análise dos componentes principais que leva em conta a variação total dos dados e desta forma, as 29 assertivas, anteriormente incorporadas em cinco grupos, redistribuíram-se em oito fatores principais que juntos explicam cerca de $66 \%$ da variação total. Os valores de KMO igual a 0,747 e do Alfa de Cronbach variando entre 0,563 e 0,867 indicam qualidade dos dados (FIELD, 2009; HAIR JR. et al., 2006). A Tabela 3 apresenta o resultado da análise fatorial das 29 assertivas e sua variância total explicada.

Tabela 3 - Análise fatorial e variância total explicada

\begin{tabular}{ccccccc}
\hline & \multicolumn{3}{c}{ Carga dos Fatores sem Rotação } & \multicolumn{3}{c}{ Carga dos Fatores com Rotação } \\
\cline { 2 - 6 } Fatores & Total & \% de Variância & $\begin{array}{c}\text { \% de Variância } \\
\text { Acumulada }\end{array}$ & Total & \% de Variância & $\begin{array}{c}\text { \% de Variância } \\
\text { Acumulada }\end{array}$ \\
& $5-75$ & $19-829$ & $19-829$ & $4-079$ & $14-066$ & $14-066$ \\
2 & $2-986$ & $10-296$ & $30-125$ & $2-959$ & $10-202$ & $24-268$ \\
3 & $2-576$ & $8-883$ & $39-008$ & $2-365$ & $8-155$ & $32-423$ \\
4 & $2-276$ & $7-849$ & $46-857$ & $2-346$ & $8-089$ & $40-512$ \\
5 & $1-582$ & $5-456$ & $52-313$ & $2-057$ & $7-093$ & $47-605$ \\
6 & $1-387$ & $4-783$ & $57-096$ & $1-872$ & $6-454$ & $54-059$ \\
7 & $1-33$ & $4-585$ & $61-681$ & $1-659$ & $5-72$ & $59-779$ \\
8 & $1-099$ & $3-788$ & $65-469$ & $1-65$ & $5-69$ & $65-469$ \\
\hline
\end{tabular}

Fonte. Elaboração propria 
O Quadro 2 apresenta os oito fatores com suas nomenclaturas, as assertivas que os compõem e medida de confiabilidade com o Alfa Cronbach.

Quadro 2 - Fatores influenciadores da Evasão, assertivas e medida de confiabilidade

\begin{tabular}{|c|c|c|}
\hline Fatores & Assertivas & $\begin{array}{l}\text { Alfa de } \\
\text { Cronbach }\end{array}$ \\
\hline $\begin{array}{l}\text { Estrutura do } \\
\quad \text { Curso }\end{array}$ & $\begin{array}{l}\text { Relacionamento entre aluno e professor } \\
\text { Método de professores } \\
\text { Qualidade dos Professores } \\
\text { Estrutura curricular } \\
\text { Relacionamento entre aluno e aluno } \\
\text { Prestígio do curso na cidade }\end{array}$ & $0-867$ \\
\hline $\begin{array}{l}\text { Escolha do } \\
\text { Curso }\end{array}$ & $\begin{array}{c}\text { Escolha inadequada do curso } \\
\text { Descobri que não tinha vocação para o curso } \\
\text { Falta de conhecimento sobre o curso escolhido } \\
\text { Mudança de Curso }\end{array}$ & $0-763$ \\
\hline Cidade & $\begin{array}{c}\text { Dificuldades em se manter em uma nova cidade } \\
\text { Dificuldades em adaptar-se em uma nova cidade } \\
\text { Mudança de cidade }\end{array}$ & $0-723$ \\
\hline $\begin{array}{l}\text { Conciliar } \\
\text { estudo e } \\
\text { trabalho }\end{array}$ & $\begin{array}{l}\text { Dificuldade em conciliar estudo com trabalho } \\
\text { Dificuldade em se manter somente estudando } \\
\text { Localização da Instituição } \\
\text { Sobrecarga de atividades }\end{array}$ & $0-646$ \\
\hline $\begin{array}{l}\text { Estrutura da } \\
\text { Instituição }\end{array}$ & $\begin{array}{l}\text { Falta de material bibliográfico } \\
\text { Instalações inadequadas } \\
\text { Greve }\end{array}$ & $0-663$ \\
\hline Pessoal & $\begin{array}{c}\text { Gravidez } \\
\text { Para cuidar de Filhos } \\
\text { Doença } \\
\text { Casamento }\end{array}$ & $0-563$ \\
\hline $\begin{array}{l}\text { Mercado de } \\
\text { Trabalho }\end{array}$ & $\begin{array}{c}\text { Oferta de emprego ou promoção } \\
\text { Pouca opção de emprego } \\
\text { Expectativa de baixa remuneração após concluir o curso }\end{array}$ & $0-596$ \\
\hline Aprendizado & $\begin{array}{c}\text { Acúmulo de reprovações } \\
\text { Dificuldades de aprendizado }\end{array}$ & $0-679$ \\
\hline
\end{tabular}

Fonte: Elaboração própria

$\mathrm{Na}$ análise fatorial foi utilizada a rotação varimax que é sugerida quando há a intenção de simplificar as linhas e colunas da matriz fatorial para facilitar a interpretação. O método varimax maximiza a soma de variância de cargas da matriz fatorial e tem se mostrado muito eficiente como uma abordagem analítica para a obtenção de uma rotação ortogonal de fatores (HAIR Jr. et al., 2006). 
Como foram descobertos novos fatores e outros se agruparam de maneira diferente, excluindo ou incluindo assertivas, se fez necessária uma readequação na nomenclatura dos fatores antes dispostos. A partir da análise foi possível identificar que os fatores Estrutura do Curso, Estrutura da Instituição, Pessoal, Mercado de trabalho que anteriormente estavam agrupados, foram divididos em fatores singulares. Também surgiram fatores novos não percebidos anteriormente, como é o caso dos fatores Escolha do Curso, Cidade, Conciliar estudo e trabalho e Aprendizado.

Alguns fatores foram encontrados na literatura existente como se pôde observar nos estudos da Comissão Especial (1996), de Gomes (1999), Polydoro (2000), Veloso e Almeida (2002) e Mello et al. (2012). Já outros, como Aprendizado, Pessoal e Cidade são novas reorganizações trazidas por esta pesquisa. Os 8 fatores estão descritos na Figura 4.

Figura 4

\begin{tabular}{|c|}
\hline $\begin{array}{c}\text { Estrutura do } \\
\text { Curso }\end{array}$ \\
\hline $\begin{array}{c}\text { Escolha do } \\
\text { Curso }\end{array}$ \\
\hline $\begin{array}{c}\text { Conciliar estudo } \\
\text { e trabalho }\end{array}$ \\
\hline $\begin{array}{c}\text { Estrutura da } \\
\text { Instituição }\end{array}$ \\
\hline Pessoal \\
\hline Mercado de \\
Trabalho
\end{tabular}

Fator formado pelas assertivas relacionadas tanto à professores, como método, qualidade e relacionamento, quanto à estrutura curricular e prestígio do curso

Fator que leva em consideração principalmente a escolha inadequada do curso, abrangendo também a mudança de um curso para outro.

Fator que abrange a dificuldade de conciliação entre atividades curriculares e trabalho, aqui também se encontram as assertivas relacionadas a finanças

Fonte: Elaboração propria

A ausência do fator Financeiro também foi uma questão intrigante na pesquisa. Polydoro (2000), Pereira (2003), Barroso e Falcão (2004) e Borges (2011) sinalizaram que a questão financeira seria um fator singular, contudo nesta pesquisa as assertivas relacionadas a finanças se dissociaram em outros fatores. 
A composição das 29 assertivas em 8 fatores, considerando os parâmetros de qualidade e confiabilidade dos dados ora apresentados, propicia a continuidade das análises e teste de hipótese, visando atender ao objetivo desta pesquisa.

Foram realizados os testes de normalidade dos dados e homogeneidade da variância para identificar que tipo de testes de hipóteses deveriam ser utilizados (testes paramétricos ou não paramétricos). Os resultados indicaram não haver normalidade dos dados da distribuição e não haver homogeneidade da variância dos fatores. Assim, procedeu-se com o uso de testes não paramétricos. A correlação de Spearman entre a variável Gênero e os fatores indicou haver significância estatística apenas com os fatores Cidade e Aprendizado, conforme Quadro 3.

A partir desta análise preliminar, busca-se testar a hipótese de haver diferenças entre os fatores que levam alunas e alunos a deixarem seus cursos.

Quadro 3 - Correlação entre fatores da evasão e a variável gênero

\begin{tabular}{|ccc|}
\hline & Correlação & Gênero \\
\hline Estrutura do Curso & Correlação & $0-132$ \\
& Sig. & $0-075$ \\
\hline Escolha do Curso & Correlação & $-0-099$ \\
& Sig. & $0-18$ \\
\hline Cidade & Correlação &, $194^{* *}$ \\
& Sig. & $0-008$ \\
\hline Conciliar estudo e trabalho & Correlação & $-0-127$ \\
& Sig. & $0-087$ \\
\hline Estrutura da Instituição & Correlação & $-0-096$ \\
& Sig. & $0-195$ \\
\hline Pessoal & Correlação & $-0-1$ \\
& Sig. & $0-176$ \\
\hline Mercado de Trabalho & Correlação & $0-118$ \\
& Sig. & $0-11$ \\
\hline Aprendizado & Correlação &, $158^{*}$ \\
& Sig. & $0-032$ \\
\hline
\end{tabular}

Fonte: Elaboração própria.

Nota: * indica nível de significância menor que $0,05, * *$ indica nível de significância menor que 0,01 . 


\subsection{Teste da hipótese desta pesquisa}

Pode-se observar na Quadro 4 que há correlação positiva a um nível de significância de 5\% entre a variável Gênero e os fatores Cidade e Aprendizado. Sendo assim, a variação do gênero implica positivamente em uma variação nos fatores Cidade e Aprendizado como influenciadores da evasão.

Quadro 4 - Comparativo entre médias para 2 variáveis - Teste de Mann-Whitney

\begin{tabular}{|lcccccccc|}
\hline & $\begin{array}{c}\text { Estrutura } \\
\text { do Curso }\end{array}$ & $\begin{array}{c}\text { Escolha } \\
\text { do } \\
\text { Curso }\end{array}$ & & Cidade & $\begin{array}{c}\text { Conciliar } \\
\text { estudo e } \\
\text { trabalho }\end{array}$ & $\begin{array}{c}\text { Estrutura } \\
\text { da } \\
\text { Instituição }\end{array}$ & $\begin{array}{c}\text { Pessoal } \\
\text { Mercado } \\
\text { de } \\
\text { Trabalho }\end{array}$ & Aprendizado \\
\hline Mann-Whitney U & 3310 & 3504 & 3044 & 3367 & 3267 & 3269 & 3733 & 3050 \\
Z & $-1-614$ & $-1-053$ & $-2-385$ & $-1-449$ & $-1-739$ & $-1-733$ & $-0-389$ & $-2-367$ \\
Sig. (2-tailed) & $0-106$ & $0-293$ & $0-017$ & $0-147$ & $0-082$ & $0-083$ & $0-697$ & $0-018$ \\
\hline
\end{tabular}

Fonte: Elaboração própria

Da mesma forma, considerando um nível de significância de 5\% é possível observar que há diferenças estatisticamente significativas entre os gêneros para os fatores Cidade e Aprendizado. Tal resultado segue representado na Tabela 6. Pode-se observar que, como o nível de significância (Sig) é menor do que 0,05 , então há diferenças estatisticamente significativa entre as os fatores Cidade e Aprendizado em relação à variável Gênero.

Alguns estudos anteriores não indicaram haver diferenças nas percepções entre homens e mulheres, e na sua maioria as pesquisas apenas apresentam o número de evadidos, que em sua maioria são homens, conforme identificado no estudo de Mello et al. (2012).

Uma forma de representar as respostas de homens e mulheres nos oito fatores identificados nesta pesquisa pode ser verificada na Figura 5. Observa-se que os fatores conciliar estudo e trabalho, pessoal, escolha do curso e estrutura da instituição são aqueles em que as mulheres indicam maior influência para a evasão do que os homens. Já para os fatores cidade, aprendizado, estrutura do curso e mercado de trabalho as mulheres indicam menor influência para a evasão do que os homens. 
Figura 5 - Dados dos fatores de evasão e um comparativo considerando a variável gênero

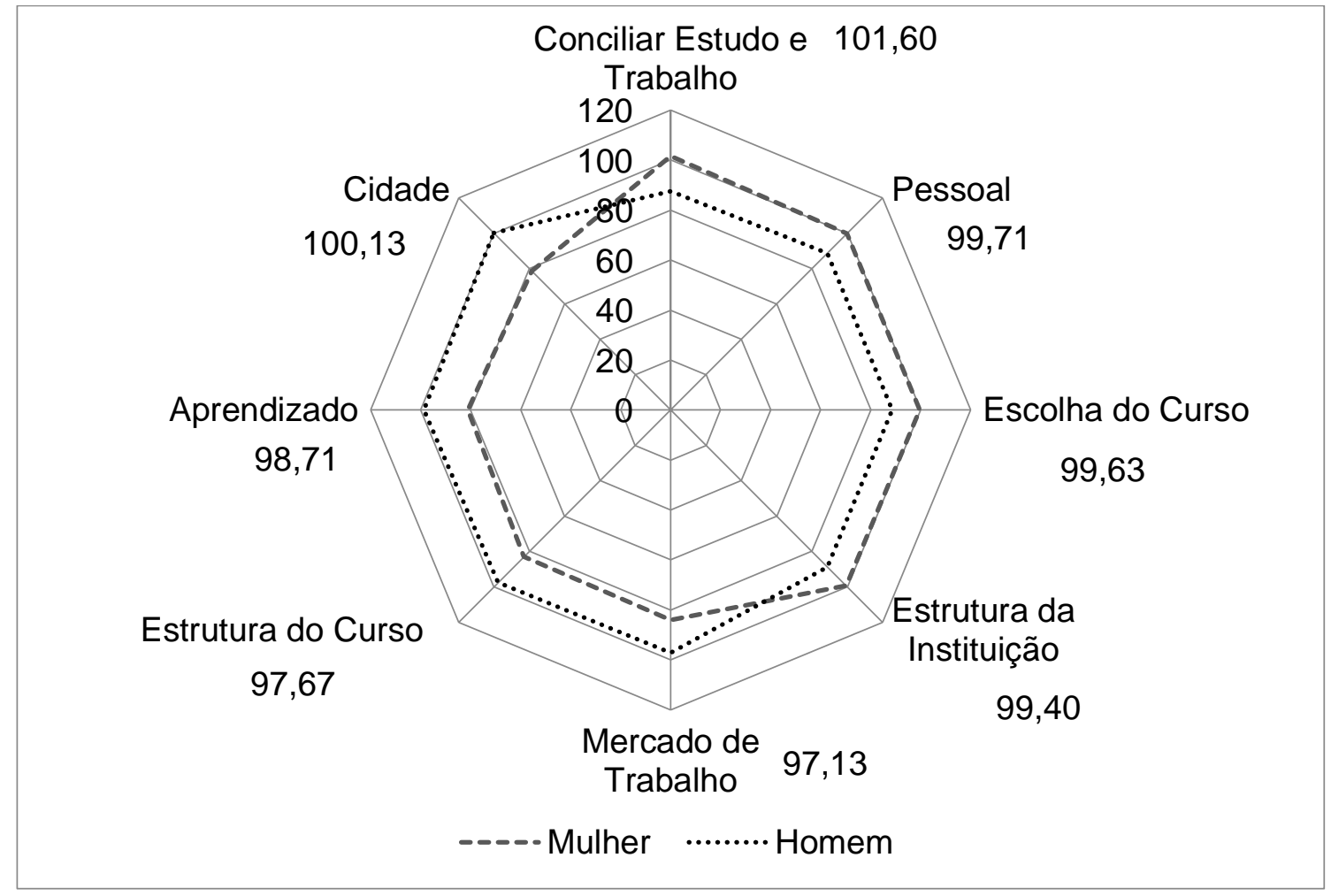

Fonte: Elaboração própria

Contudo, após a análise fatorial os resultados indicam que há diferenças estatisticamente significativas a um nível de significância de 0,05 entre as razões de evasão o gênero, apenas para as categorias Cidade e Aprendizado. Para todas as demais categorias, mesmo havendo certa diferença (Figura 5), pode-se dizer que não há diferenças estatisticamente significativas a um nível de significância de 0,05 entre as razões de evasão entre homens e mulheres.

Pode-se indicar que essas diferenças de percepções estariam associadas à certa subjetividade, valores pessoais, prioridades e experiências de cada pessoa, contudo a identificação destas particularidades está além do objetivo desta pesquisa. De toda sorte, os dados analisados confirmam a hipótese, ou seja, há diferenças estatisticamente significativas entre as razões de evasão (Cidade e Aprendizagem) de acordo com o gênero.

Como próximo passo analítico, foram analisadas as respostas dadas às questões abertas como forma de evidenciar as descobertas da análise quantitativa. Assim, são apresentadas algumas evidências de cada um dos oito fatores de evasão e identificados outros dois, conforme mostra o Quadro 5. 
As respostas das alunas foram quanto ao excesso de atividades que dificultaram a conciliação estudo e trabalho, questões pessoais como a doença do pai, Esposo não apoiar, ter ficado viúva e pelo fim do casamento, além da falta de compreensão de alguns professores, mudança de curso, mudança de cidade, condições financeiras, ausência de moradia, dificuldade de acompanhar as disciplinas e não aproveitamento de disciplinas.

As respostas dos alunos foram pautadas em problemas com professores e alunos, excesso de atividades extra sala, falta de tempo para estudar, muitas reprovações, falta de professores para as disciplinas, por achar que o curso não prepara para o mercado, pelo curso ser novo, mudança de curso, mudança de cidade, localização do campus e distância de Rondonópolis de grandes centros, não conseguir emprego nem bolsas auxílio, não conseguir transferência para o noturno, falta de recursos para moradia, alimentação e locomoção, e falta de alojamento.

Aproveitando-se do que indica Marshall (1995), a análise dos dados apresentada neste artigo busca superar os desafios de como lidar com as diferenças aparentes entre homens e mulheres como parte de um grupo social definido, neste caso, alunos e alunas evadidos de uma IES pública.

Pela análise das respostas de alunas e alunos, por um lado, é possível reforçar o que é indicado na Figura 5, ou seja, quais os fatores que mais contribuem para a evasão de mulheres e homens. Por outro lado, os problemas de segurança e ausência de linhas de pesquisa e cursos de extensão apareceram como elementos a serem incorporados em estudos futuros, pois não apareceram em estudos anteriores sobre evasão e são considerados particularidades do Campus da UFMT de Rondonópolis.

Aproveitando-se do que indica Marshall (1995), a análise dos dados apresentada neste artigo busca superar os desafios de como lidar com as diferenças aparentes entre homens e mulheres como parte de um grupo social definido, neste caso, alunos e alunas evadidos de uma IES pública.

Pela análise das respostas de alunas e alunos, por um lado, é possível reforçar o que é indicado na Figura 5, ou seja, quais os fatores que mais contribuem para a evasão de mulheres e homens. Por outro lado, os problemas de segurança e ausência de linhas de pesquisa e cursos de extensão apareceram como elementos a serem incorporados em estudos futuros, pois não apareceram em estudos anteriores sobre evasão e são considerados particularidades do Campus da UFMT de Rondonópolis. 
Quadro 5 - Respostas às perguntas abertas evidenciando os fatores de evasão

\begin{tabular}{|c|c|c|}
\hline Fatores & Homens & Mulheres \\
\hline $\begin{array}{l}\text { Estrutura do } \\
\text { Curso }\end{array}$ & $\begin{array}{l}\text { Metodologias que prejudicavam os estudantes } \\
\text { trabalhadores; } \\
\text { Despreparo dos alunos que ingressaram no } \\
\text { curso; } \\
\text { Muitos trabalhos e exercícios extra sala; } \\
\text { Falta de cuidado no tratamento de alguns } \\
\text { professores; } \\
\text { Falta de professores para as disciplinas; } \\
\text { O curso não prepara para o mercado de } \\
\text { trabalho. }\end{array}$ & A falta de compreensão de alguns professores \\
\hline $\begin{array}{l}\text { Escolha do } \\
\text { Curso }\end{array}$ & $\begin{array}{l}\text { Passei para o cargo de professor substituto; } \\
\text { O fato do curso estar iniciando as atividades } \\
\text { no campus; } \\
\text { Desisti do curso para tentar um diferente. }\end{array}$ & $\begin{array}{l}\text { Beneficiar do Prouni e fazer Direito; } \\
\text { Decidi seguir a carreira pela qual me formei; } \\
\text { Estava concluindo Ciências Contábeis. }\end{array}$ \\
\hline Cidade & $\begin{array}{l}\text { Devido à família morar em Goiânia; } \\
\text { Não consegui emprego e nem bolsas auxílio; } \\
\text { Distância de Rondonópolis a grandes centros. }\end{array}$ & $\begin{array}{l}\text { Fui transferida para outra cidade } \\
\text { Condições financeiras e ausência de moradia } \\
\text { Tive que mudar para Cuiabá }\end{array}$ \\
\hline $\begin{array}{l}\text { Conciliar } \\
\text { Estudo e } \\
\text { Trabalho }\end{array}$ & $\begin{array}{l}\text { Não consegui transferência para o noturno; } \\
\text { Viajo muito e estava fazendo eu faltar muito; } \\
\text { Não dispunha de tempo para estudar. }\end{array}$ & Excesso de atividades não deixava conciliar \\
\hline $\begin{array}{l}\text { Estrutura da } \\
\text { Instituição }\end{array}$ & $\begin{array}{l}\text { Estruturas nas universidades federais são } \\
\text { precárias; } \\
\text { Localização do campus; } \\
\text { Dificuldade de locomoção para a faculdade. }\end{array}$ & \\
\hline Pessoal & $\begin{array}{l}\text { Perda de visão; } \\
\text { Fiquei desempregado; } \\
\text { Falta de recursos para a moradia, alimentação } \\
\text { e locomoção; } \\
\text { Falta de alojamentos e problemas pessoais. }\end{array}$ & $\begin{array}{l}\text { Doença de meu pai } \\
\text { Esposo não apoiar } \\
\text { Fiquei viúva } \\
\text { Fim do casamento conturbado } \\
\end{array}$ \\
\hline $\begin{array}{l}\text { Mercado de } \\
\text { Trabalho }\end{array}$ & $\begin{array}{l}\text { Transição de profissão e empresa; } \\
\text { Passou no concurso da PM; } \\
\text { O curso não me traria benefícios à profissão. }\end{array}$ & Novo cargo me levou a procurar outro curso \\
\hline Aprendizado & $\begin{array}{l}\text { Aula de matemática muitos não sabiam fazer } \\
\text { regra de } 3 \text {; } \\
\text { Tive muitas reprovações. }\end{array}$ & $\begin{array}{l}\text { Não consegui acompanhar as disciplinas } \\
\text { Não aproveitamento das disciplinas }\end{array}$ \\
\hline Segurança & $\begin{array}{l}\text { Medo de ser assaltado novamente; } \\
\text { casa/faculdade/serviço. }\end{array}$ & Fui assaltada, levaram minha moto \\
\hline $\begin{array}{l}\text { Pesquisas e } \\
\text { Extensão }\end{array}$ & $\begin{array}{l}\text { Falta de projetos de pesquisa no curso; } \\
\text { Sem projetos de iniciação científica e poucos } \\
\text { de extensão. }\end{array}$ & \\
\hline
\end{tabular}

Fonte: Elaboração própria 


\section{Considerações Finais}

O recorte desta pesquisa envolvendo o fenômeno da evasão no ensino superior e a diversidade de gênero propiciou um detalhamento e um aprofundamento desses elementos. Os dados aqui apresentados revelam que há diferenças entre as razões de evasão de acordo com o gênero. Foi possível encontrar diferenças estatisticamente significativas, a um nível de significância de 0,05 , em relação aos fatores Cidade e Aprendizado.

Além disso, o estudo revelou que entre as razões que provocam a evasão, há fatores relacionados ao curso e à instituição de ensino, e que a evasão não é um processo dependente apenas do aluno, reforçando o que apresentam Veloso e Almeida (2002), mas é um fenômeno institucional, refletindo uma carência de políticas consistentes que colaborem na permanência do aluno no curso de sua opção, conforme indicam outros autores (AMBIEL; SANTOS; DALBOSCO, 2016; BERGAMO; FARAH; GIULIANI, 2007; MENDONÇA et al., 2012).

Ademais, os impactos da evasão, não só prejudicam as metas de desempenho das instituições de ensino superior (PLATT NETO; CRUZ; PFITSCHER, 2008), mas levam a uma redução do potencial capital social de uma sociedade (NAGAI; CARDOSO, 2017). $\mathrm{O}$ aluno que se torna evadido do ensino superior pode ter impacto negativo em sua empregabilidade, podendo desenvolver sentimentos de fracasso e de incapacidade intelectual. Da mesma forma, a universidade pública falha em cumprir seu papel de formar pessoas que contribuam com a sociedade, tornando-se ineficiente no processo ensino-aprendizagem. Por último, a sociedade de uma forma geral também acaba perdendo em cidadania e capital social.

A contribuição prática desta pesquisa está em prover em informações úteis para os cursos envolvidos que podem se valer dessas para estruturar medidas que visem a redução da evasão. Descobrir os motivos da evasão e as dificuldades enfrentadas pelos alunos e pelas alunas, reconhecendo que homens e mulheres possuem necessidades diferentes, pode levar a novas estratégias visando à retenção de cada grupo, provendo medidas comuns entre os gêneros, pois a maioria dos fatores de evasão encontrados neste estudo não demonstraram estar associada a apenas um dos gêneros, mas algumas específicas para cada um dos gêneros. 
Para estudos futuros, sugere-se, especialmente em um momento em que se aproxima o desmembramento do Campus para a criação da UFR - Universidade Federal de Rondonópolis (Lei 13.637/2018 de 20/03/2018), poder-se-ia realizar uma pesquisa com todos os cursos de maneira a identificar os fatores que levam à evasão, suas similaridades e suas dissimilaridades a partir da diversidade de seus alunos, incluindo questões de gênero, etnia, idade, origem e iniciar medidas para reduzir o número de alunos que desistem de seus cursos.

A evasão ou a não continuidade dos cidadãos na universidade caminha em direção oposta ao desenvolvimento local, regional e nacional, pois o potencial capital social de uma sociedade é uma importante ferramenta que auxiliaria no progresso econômico e social, e no fortalecimento da democracia. A adoção imediata de políticas contra ao fenômeno evasão universitária deve ser priorizada.

\section{Referências}

ADACHI, A. A. C. T. Evasão e evadidos nos cursos de graduação da Universidade Federal de Minas Gerais. Belo Horizonte, 2009. 214 f. Dissertação - Mestrado em Educação, UFMG/FaE.

AMBIEL, R. A. M. Construção da Escala de Motivos para Evasão do Ensino Superior. Avaliação Psicológica, v. 14, n. 1, p. 41-52, 2015.

AMBIEL, R. A. M.; SANTOS, A. A. A. DOS; DALBOSCO, S. N. P. Motivos para evasão, vivências acadêmicas e adaptabilidade de carreira em universitários. Psico, v. 47, n. 4, p. $288-$ 297, 2016.

ATAÍDE, J. S. P.; LIMA, L. M.; ALVES, E. de O. A repetência e o abandono escolar no curso de licenciatura em física: um estudo de caso. Revista Physicae. v. 6, 2006.

BAGGI, C. A. D. S.; LOPES, D. A. Evasão e avaliação institucional no ensino superior: Uma discussão bibliográfica. Avaliação, Campinas; Sorocaba, SP, v. 16, n. 2, p. 355-374, 2011.

BARDAGI, M. P.; HULZ, C. S. Não havia outra saída: Percepções de alunos evadidos sobre o abandono do curso superior. Psico-UFS, v. 14, n. 1, p. 95-105, 2009.

BARDAGI, M.; HUTZ, C. S. Evasão universitária e serviços de apoio ao estudante: Uma breve revisão da literatura brasileira. Psic. Rev. São Paulo, v. 14, n. 2, p. 279-301, 2005.

BARROSO, M. F.; FALCÃO, E. B. M. EVASÃO UNIVERSITÁRIA: O CASO DO INSTITUTO DE FÍSICA DA UFRJ. Anais...IX Encontro Nacional De Pesquisa Em Ensino De Física. Jaboticatubas, 2004.

BERGAMO, F.; FARAH, O. E.; GIULIANI, A. C. A lealdade e a educação superior: Ferramenta estratégica para a retenção de clientes. Revista Gerenciais, v. 6, n. 1, p. 55-62, 2007.

BORGES, S. M. Fatores determinantes da evasão escolar no ensino superior: o estudo de caso do ILES/ULBRA de Itumbiara. Goiânia, 2011. 77 f. Dissertação (mestrado), Programa de PósGraduação Stricto Sensu. Mestrado Profissional em Desenvolvimento Regional, Faculdades Alves Faria. 
CENSO DEMOGRÁFICO 2010. Características da população e dos domicílios: resultados do universo. Rio de Janeiro: IBGE, 2011. Disponível em: <https://sidra.ibge.gov.br/home/ipca15/brasil>. Acesso em: jun. 2018.

COMISSÃO ESPECIAL DE ESTUDOS SOBRE A EVASÃO (MEC/ANDIFES/ABRUEM/SESU). Diplomação, retenção e evasão nos cursos de graduação em instituições de ensino superior públicas. Brasília, 1996.

COSTA, F. J. DA; BISPO, M. DE S.; PEREIRA, R. DE C. DE F. Dropout and retention of undergraduate students in management: a study at a Brazilian Federal University. RAUSP Management Journal, v. 53, p. 74-85, 2018.

CUNHA, J. V. A. DA et al. Quem está ficando para trás? Uma década de evasão nos cursos brasileiros de graduação em administração de empresas e ciências contábeis. Revista de Educação e Pesquisa em Contabilidade, v. 9, n. 2, p. 124-142, 2015.

CUNHA, J. V. A. DA; NASCIMENTO, E. M.; DURSO, S. DE O. Razões e influências para a evasão universitária: Um estudo com estudantes ingressantes nos cursos de ciências contábeis de instituições públicas federais da região sudeste. Advances in Scientific and Applied Accounting, v. 9, n. 2, p. 141-161, 2016.

ELY, R. J.; THOMAS, D. A. Cultural diversity at work: the effects of diversity perspective on work group processes and outcomes. Administrative Science Quarterly, v. 46, p. 229-273, 2001.

FIELD, A. Descobrindo a estatística usando o SPSS. $2^{\text {a }}$ ed. Porto Alegre. Artmed, 2009.

FURTADO, V. V. A.; ALVES, T. W. Fatores determinantes da evasão universitária: uma análise com alunos da UNISINOS. Revista Contemporânea de Economia e Gestão, v. 10, n. 2, p. 115129, 2012.

GOMES, A. A. Evasão e Evadidos: O discurso dos alunos sobre evasão escolar nos cursos de licenciatura. Nuances. Vol. V - jul 1999.

HAIR JR. F.; ANDERSON, R. E.; TATHAM, R. C.; BLACK, W. C. M. Análise Multivariada de dados. Porto Alegre: Bookman, 2006.

HANASHIRO, D.M.M. Convivendo com a diversidade cultural. In: HANASHIRO, D.M.M.; TEIXEIRA, M.L.M.; ZACCARELLI, L.M. (Orgs.) Gestão do fator humano: uma visão baseada em stakeholders. São Paulo: Saraiva, 2008, p. 45-111.

HANASHIRO, D.M.M.; TEIXEIRA, M.L.M.; ZACCARELLI, L.M. (Orgs.) Gestão do fator humano: uma visão baseada em stakeholders. São Paulo: Saraiva, 2004

HARRISON, D. A.; PRICE, K. H.; BELL, M. P. Beyond relational demography: Time and the efferts of surface - and deep-level diversity on work group cohesion. Academy of Management Journal, v. 41, n. 1, 1998, p. 96-107.

MACHADO, M. R. A evasão nos cursos de agropecuária e informática / nível técnico da Escola Agrotécnica Federal de Inconfidentes - MG (2002-2006). Brasília, 2009. 136 f. Dissertação (Mestrado em Educação), Universidade de Brasília.

MARSHALL, J. (1995). Researching women and leadership: some comments on challenges and opportunities. International Review of Women and Leadership. v.1, n.1, pp. 1-10.

MAZZETTO, S. E.; CARNEIRO, C. C. B. e S.; Licenciatura em Química da Ufc: Perfil SócioEconômico, Evasão e Desempenho dos Alunos. Quim. Nova, Vol. 25, No. 6B, 1204-1210, 2002. 
MELLO, S. P. T. de; SANTOS, E. G. dos; SOARES, A. C.; REZENDE; A. M. C. A evasão no curso de administração: diagnostico e possibilidades em uma Universidade pública no sul do brasil. Anais...XXIII ENANGRAD. Bento Gonçalves, 2012.

MENDONÇA, C. M. C. de; SOUZA, T.; CAMPOS, D. F.; NÓBREGA, K. C. Análise Da Importância, Desempenho e Influência de Serviços na Retenção de Alunos em Curso de Administração. Revista Gestão e Planejamento, Salvador, v. 13, n. 2, p. 294-314, maio/ago. 2012.

NAGAI, N. P.; CARDOSO, A. L. J. A evasão universitária: Uma análise além dos números. Revista Estudo \& Debate, v. 24, n. 1, p. 193-215, 2017.

PEREIRA, F. C. B. Determinantes da evasão de alunos e os custos ocultos para as Instituições de Ensino Superior. Florianópolis, 2003. 172 f. Tese (Doutorado) Engenharia de Produção Universidade Federal de Santa Catarina.

PEREIRA, J. T. V. Uma contribuição para o entendimento da evasão. Um estudo de caso: Unicamp. Revista da avaliação da educação superior, v. 1, n. 2. São Paulo, 1996.

PLATT NETO, O. A.; CRUZ, F. DA; PFITSCHER, E. D. Utilização de metas de desempenho ligadas à taxa de evasão escolar nas universidades públicas. Revista de Educação e Pesquisa em Contabilidade, v. 2, n. 2, p. 54-74, 2008.

POLYDORO, S. A. J. O trancamento de matrícula na trajetória acadêmica do universitário: condições de saída e retorno à instituição. Campinas, 2000, [s.n], Tese (Doutorado) Educação Faculdade de Educação - UNICAMP.

PRESTES, E. M. Da T.; FIALHO, M. G. D.; PFEIFFER, D. K. A evasão no ensino superior globalizado e suas repercussões na gestão universitária. João Pessoa, 2014.

RIBEIRO, M. A. O Projeto Profissional Familiar como Determinante da Evasão Universitária Um Estudo Preliminar. Revista Brasileira de Orientação Profissional, 2005, 6 (2), p. 55-70.

RODRIGUES, D. S.; SANTOS, N. DE A.; SANTANA, M. DA S. Growth or retraction: What tendencies do indices for vacancy offer, registrations and number of graduates in brazilian accounting science programs expose? Gestão Finanças e Contabilidade, v. 5, n. 1, p. 105-122, 2015.

SCHUARCZ, L. D. et al. Secretaria ou não secretariar? Eis a questão: Um estudo sobre a evasão no curso de secretariado executivo. Revista de Gestão e Secretariado, v. 5, n. 1, p. 19-41, 2011.

SILVA FILHO, R. L. L.; MOTEJUNAS, P. R.; HIPÓLITO, O.; LOBO, M. B. de C. M. A evasão no ensino superior brasileiro. Cadernos de Pesquisa, v. 37, n. 132, p. 641-659, set./dez, 2007.

STOCKDALE, M. S.; CROSBY, F. J. The psychology and management of workplace diversity. Blackwell, 2006.

THOMAS JR., R. R. Redefining diversity. New York: AMACON, 1996.

VELOSO, T. C. M. A.; ALMEIDA, E. P. Evasão nos cursos de graduação da Universidade Federal de Mato Grosso, campus universitário de Cuiabá: Um processo de exclusão. Cuiabá: UFMT. 2002. 